\title{
EGU2020-20534
}

https://doi.org/10.5194/egusphere-egu2020-20534

EGU General Assembly 2020

(c) Author(s) 2020. This work is distributed under

the Creative Commons Attribution 4.0 License.

\section{Sustainable water use for rice agro-ecosystems in northern Italy}

Arianna Facchi ${ }^{1}$, Alice Mayer ${ }^{1}$, Enrico Chiaradia ${ }^{1}$, Andrea Ricciardelli ${ }^{2}$, Michele Rienzner ${ }^{1}$, Bianca Ortuani ${ }^{1}$, Olfa Gharsallah ${ }^{1}$, Claudio Gandolfi ${ }^{1}$, and Marco Romani ${ }^{2}$

'Dipartimento di Scienze Agrarie e Ambientali - Produzione, Territorio, Agroenergia, Università degli Studi di Milano (DiSAAUNIMI), via Celoria 2, Milano (arianna.facchi@unimi.it)

${ }^{2}$ Centro Ricerche Riso, Ente Nazionale Risi (CRR-ENR), strada per Cerretto, Pavia

In the Mediterranean basin, rice is cultivated over an area of 1,300,000 hectares. The most important rice-producing countries are Italy and Spain in Europe (72\% of the EU production; 345,000 ha), and Egypt and Turkey among the extra-EU countries (almost totality of the production; 789,000 ha). Traditionally, rice is grown under continuous flooding; thus, it requires much more irrigation than non-ponded crops. The MEDWATERICE project (PRIMA-Section 2-2018; https://www.medwaterice.org/) aims at exploring sustainability of innovative rice irrigation management solutions, in order to reduce rice water consumption and environmental impacts, and to extend rice cultivation outside of traditional paddy areas to meet the escalating demand. Within the MEDWATERICE project, irrigation management options to address the main site-specific problems are being tested for each rice areas involved in the project (IT, ES, PT, EG, TR). Case studies are being conducted in pilot farms, with the involvement of Stake-Holder Panels (SHPs) in each country. Data collected at the farm level will be extrapolated to the irrigation district level, to support water management decisions and policies. Moreover, indicators for quantitative assessment of environmental, economic and social sustainability of the irrigation options will be defined.

This work illustrates the first year of results for the Italian Case Study (Lomellina area, Pavia) at the pilot farm scale. This area is characterized by a growing water scarcity in drought years in many districts. Within the farm managed by the National Rice Research Center (CRR), in the agricultural season 2019 the experimentation was conducted in six plots of about $20 \mathrm{~m} \times 80 \mathrm{~m}$ each, with two replicates for each of the following water regimes: i) water-seeded rice with continuous flooding (WFL), ii) dry-seeded rice with continuous flooding from the 3-4 leaf stage (DFL), and iii) water seeded-rice with alternate wetting and drying from fertilization at the tillering stage (AWD). One out of the two replicates of each treatment was instrumented with: water inflow and outflow meters, set of piezometers, set of tensiometers and water tubes for the irrigation management in the AWD plots. A soil survey was conducted before the agricultural season (EMI sensor and physico-chemical analysis of soil samples). Periodic measurements of crop biometric parameters (LAl, crop height, crop rooting depth) were performed. Moreover, nutrients ( $\mathrm{TN}, \mathrm{NO}_{3}, \mathrm{PO}_{4}, \mathrm{~K}$ ) and two widely used pesticides (Sirtaki - a.i. Clomazone; Tripion E - a.i. MCPA) were measured in irrigation water (inflow and outflow), groundwater, and porous cups installed at two soil depths (20 and $70 \mathrm{~cm}$, above and below the plough pan). Finally, rice grain yields and quality (As and Cd in 
the grain) were determined. First results in terms of cumulative water balance components (rainfall, irrigation inflow and outflow, difference in soil and ponding water storage, evapotranspiration, net percolation), water application efficiency (evapotranspiration over net water input), and water productivity (grain production over net water input), will be presented and discussed. Results of a 1D Richard-equation-based numerical simulation model applied to generalize results obtained under the different irrigation regimes will be moreover illustrated. 